Revue bibliographique pour le domaine irano-aryen

Volume 37-38-39 | 2018

Comptes rendus des publications de 2014-2016

\title{
Carlo Lippolis, Niccolò Manassero. "Storehouses and Storage Practices in Old Nisa (Turkmenistan)"
}

Julien Cuny

\section{OpenEdition}

1 Journals

\section{Édition électronique}

URL : http://journals.openedition.org/abstractairanica/47209

DOI : 10.4000/abstractairanica.47209

ISBN : 1961-960X

ISSN : 1961-960X

Éditeur :

CNRS (UMR 7528 Mondes iraniens et indiens), Éditions de l'IFRI

Référence électronique

Julien Cuny, « Carlo Lippolis, Niccolò Manassero. "Storehouses and Storage Practices in Old Nisa

(Turkmenistan)" », Abstracta Iranica [En ligne], Volume 37-38-39 | 2018, document 76, mis en ligne le 30 décembre 2018, consulté le 02 octobre 2020. URL : http://journals.openedition.org/abstractairanica/ 47209 ; DOI : https://doi.org/10.4000/abstractairanica.47209

Ce document a été généré automatiquement le 2 octobre 2020.

Tous droits réservés 


\title{
Carlo Lippolis, Niccolò Manassero. "Storehouses and Storage Practices in Old Nisa (Turkmenistan)"
}

\author{
Julien Cuny
}

\section{RÉFÉRENCE}

Carlo Lippolis, Niccolò Manassero. "Storehouses and Storage Practices in Old Nisa

(Turkmenistan)”, Electrum, 22, 2015, p. 115-142

1 Entre 2007 et 2015, la mission italienne a entrepris des fouilles dans la partie sud de la "Vieille Nisa», qui n'avait pas été touchée par fouilles des Russes. En plusieurs secteurs, et particulièrement dans un ensemble de constructions au sud-ouest un grand nombre de jarres alignées le long de murs ont été trouvées calées dans la terre, parfois enterrées au tiers ou même complètement enfouies. Certaines sont hors des structures construites tandis que d'autres sont concentrées dans certains espaces du complexe sud-ouest, jusqu'à une vingtaine dans une même salle. L'ouverture de ces grandes jarres, lorsque la partie haute est conservée, est scellée par une pierre. Les analyses physico-chmiques de l'intérieur n'ont pas donné de résultats, pas plus que dans celles de la Trésorerie au nord du site, fouillées jadis, alors que les milliers d'ostraca trouvés alors témoignent de l'importance du vin. Dans les nouvelles fouilles, les ostraca sont souvent à côté d'une jarre, mais il semble qu'ils pouvaient être réutilisés plusieurs fois après avoir été effacés. Dans une salle, la datation est homogène, entre 107 et 86 av.n.è.

2 Les nombreux scellements de jarres retrouvés (il n'y a pas de bulles) portent des signes ou des petites cavités, mentionnant peut-être la quantité de liquide contenu. Les motifs des empreintes de sceaux sont peu variés mais l'ensemble mérite une étude plus complète en préparation. 


\section{AUTEURS}

\section{JULIEN CUNY}

Conservateur au Musée du Louvre, Paris 